\title{
Rheumatoid aortic valve prolapse requiring emergency aortic valve replacement
}

\author{
DAVID C LINCH, DAVID J GILLMER, ${ }^{1}$ WILLIAM F WHIMSTER, \\ JOHN R W KEATES
}

From the Medical Unit and Department of Cardiology, University College Hospital; and the Department of Pathology and Cardiothoracic Unit, King's College Hospital, London

SUMMARY Rapid progression of aortic regurgitation was closely observed in a patient with severe seropositive rheumatoid arthritis. Rheumatoid changes within the aortic valve leaflets resulted in severe prolapse necessitating emergency operation. The postoperative course was satisfactory.

Rheumatoid heart disease has been well recognised since Charcot's original description of rheumatoid pericarditis nearly 100 years ago (Charcot, 1881). Rheumatoid granulomata affecting the heart were first described in 1941 (Baggenstoss and Rosenberg, 1941) and since then many reports have appeared describing these specific lesions in all parts of the heart. Necropsy studies have shown an 11 per cent frequency of fibrinoid granulomata within the hearts of patients with rheumatoid arthritis (Barker, 1971), though this is probably an over-estimate arising from case selection. Aortic regurgitation is well recognised in this condition, though, if ankylosing spondylitis is excluded, it is rare, usually haemodynamically insignificant, and contributes little to the overall morbidity (Weintraub and Zvaifler, 1963). There are several reports of patients requiring aortic valve replacement, but in those cases in which there is adequate clinical and histological information the progression of the regurgitant valve lesion has with one exception been slow (Barker, 1971; Iveson et al., 1975). These previous reports suggest that the regurgitation has been the result of either aortitis with dilatation of the aortic ring, or fibrosis, contraction, and destruction of the valve leaflets. We report a case of rapidly progressive aortic regurgitation caused by prolapse of leaflets softened and swollen by the rheumatoid process.

\section{Case report}

The patient was a white man born in 1912. At the age of 12 years he had an illness with arthralgia affecting many joints. There were no stigmata of

${ }^{1}$ Present address: Cardiac Department, Wentworth Hospital, Durban, South Africa. carditis at that time. He was first seen at University College Hospital in 1969 when he presented with a classical history of angina pectoris. Good symptomatic relief was obtained with glyceryl trinitrate tablets. No abnormal signs were found on examination, and chest $x$-ray film and electrocardiogram were normal.

The following year he developed an arthritis predominantly affecting the hands and feet. A clinical diagnosis of rheumatoid arthritis was supported by the finding of high titres of rheumatoid factor in the blood. Since that time, relentless joint destruction has occurred despite the use of gold, penicillamine, and long-term steroid therapy, and he has also had recurrent episcleritis and a gastric ulcer. In April 1976, he had a transient episode of second degree heart block with Wenckebach phenomenon, and in September 1977 he had an episode of atrial flutter. It was thought that he might have a rheumatoid granuloma within the conducting tissue. In November 1977, he was admitted to another hospital with a flare-up of his arthritis and worsening angina. An episode of atrial fibrillation occurred but at all times the blood pressure was normal and there was no evidence of heart failure or myocardial infarction. On this admission an apical systolic murmur was heard for the first time. An echocardiogram performed in December 1977 was normal; in particular, there was no fluttering of the mitral valve.

In January 1978, he was admitted to University College Hospital with acute dyspnoea, and found to have severe rheumatoid changes in most peripheral joints and the cervical spine. The lumbar spine and sacroiliac joints were not involved. Rheumatoid nodules were present on both elbows. $\mathrm{He}$ was in sinus rhythm at 120 per minute with a normal pulse and a blood pressure of $140 / 90 \mathrm{mmHg}$. 
The apex beat was displaced $2 \mathrm{~cm}$ laterally but was not thrusting. There was an ejection systolic murmur and a soft early diastolic murmur at the left sternal edge. There were bilateral basal crepitations but no signs of right heart failure. A chest $x$-ray film showed a cardiac diameter of $16.5 \mathrm{~cm}$ and upper lobe vein blood diversion. The electrocardiogram was normal: there was no evidence of left ventricular hypertrophy or myocardial infarction. The serum levels of cardiac enzymes were not raised. The haemoglobin was $11.7 \mathrm{~g} / \mathrm{dl}$, white blood count $6.2 \times 10^{9} / 1$, and erythrocyte sedimentation rate $77 \mathrm{~mm}$ in the first hour. The response to a small dose of diuretic was dramatic. The aortic regurgitation was thought to be haemodynamically insignificant and his deterioration before admission was attributed to a transient arrhythmia. An echocardiogram showed a normal left ventricle, fluttering of the anterior cusp of the mitral valve, and a normal aortic valve and aortic root. During this admission he had minor exacerbations of arthritis associated with fever, malaise, and a rise in erythrocyte sedimentation rate to $120 \mathrm{~mm}$ in the first hour. There were no stigmata of bacterial endocarditis and repeated blood cultures were negative.

He was readmitted in pulmonary oedema on 11 March 1978. The signs of mild aortic regurgitation were unchanged with a blood pressure of $140 / 90$ $\mathrm{mmHg}$. The pulse was normal in character and the rhythm was sinus. There was no evidence of myocardial infarction. $\mathrm{He}$ again responded to diuretic therapy, though less quickly than before. His arthritis was still active, he was intermittently pyrexial, and he had an episode of episcleritis. On 22 March he developed a sinus tachycardia of 120 per minute with a collapsing pulse. The blood pressure fell to $100 / 30 \mathrm{mmHg}$. The murmur of aortic regurgitation was audible at the left sternal edge and there was also a mid-diastolic Austin Flint murmur at the apex. He developed severe left and then right sided heart failure which was resistant to medical treatment. Blood cultures, Coxiella antibody titre, fungal antibody tests, and ASO titre were all negative. An echocardiogram showed a slightly increased left atrial diameter of $4 \mathrm{~cm}$, a left ventricular end-diastolic diameter of $5.5 \mathrm{~cm}$, ejection fraction of approximately 70 per cent; the aortic valve and aortic root appeared normal, the fluttering mitral valve was seen to close prematurely, indicating severe aortic regurgitation of acute onset, and a pericardial effusion was also shown.

He was transferred to King's College Hospital for cardiac catheterisation and operation. The left ventriculogram was normal with an ejection fraction greater than 70 per cent. The aortogram confirmed the severe aortic regurgitation. Coronary angio- grams showed a 90 per cent stenosis in the left anterior descending artery before the origin of its diagonal branch but no other stenoses.

At operation on 3 April 1978, $250 \mathrm{ml}$ creamy fluid were found within a thickened pericardium. The aortic valve was tricuspid. There were no vegetations, and all three cusps were thickened and very soft. The left coronary cusp appeared to be prolapsing. There was no dilatation of the aortic ring. The aortic valve was replaced with a $25 \mathrm{~mm}$ Carpentier Edwards xenograft, and a saphenous vein graft was placed in the left anterior descending coronary artery.

The postoperative course has been satisfactory with all wounds healing well. He has had no further angina or signs or symptoms of heart failure and has returned home. He has had one further severe exacerbation of arthritis affecting the knees and ankles.

Histological examination of the thickened pericardium showed a chronic inflammatory infiltrate containing many plasma cells. Palisading was present along the surface as seen in a rheumatoid nodule. Sections of the aortic wall were normal. The thickening of the aortic valve cusps was the result of necrotic, partly calcified tissue lying between bands of connective tissue infiltrated by inflammatory cells (Fig. a, b). Palisading at the junction between normal valve tissue and the necrotic zone was poorly defined. The appearances were not pathognomonic of rheumatoid disease, but no other diagnosis was tenable.

\section{Discussion}

Necropsy studies have shown that there are two distinct histological types of rheumatoid heart disease: a non-specific inflammation with fibrosis, and a specific process (Bywaters, 1950; Sokoloff, 1953; Roberts et al., 1968). The specific lesions are (a) the rheumatoid granulomata which are indistinguishable from the subcutaneous rheumatoid nodule and (b) a pathognomonic granulomatous and non-granulomatous inflammation occurring within a valve leaflet leaving a thin layer of uninvolved valve tissue necrotic material. This is clearly distinct from the valve lesion of rheumatic fever, carcinoid disease, or infective endocarditis (Roberts et al., 1968). To make a firm diagnosis of rheumatoid heart disease, these specific histological features must be present. Our patient had both the classical rheumatoid involvement of both aortic valve and pericardium.

Operation became necessary in this patient within four months of the first appearance of an aortic regurgitant murmur, and 12 days after an 


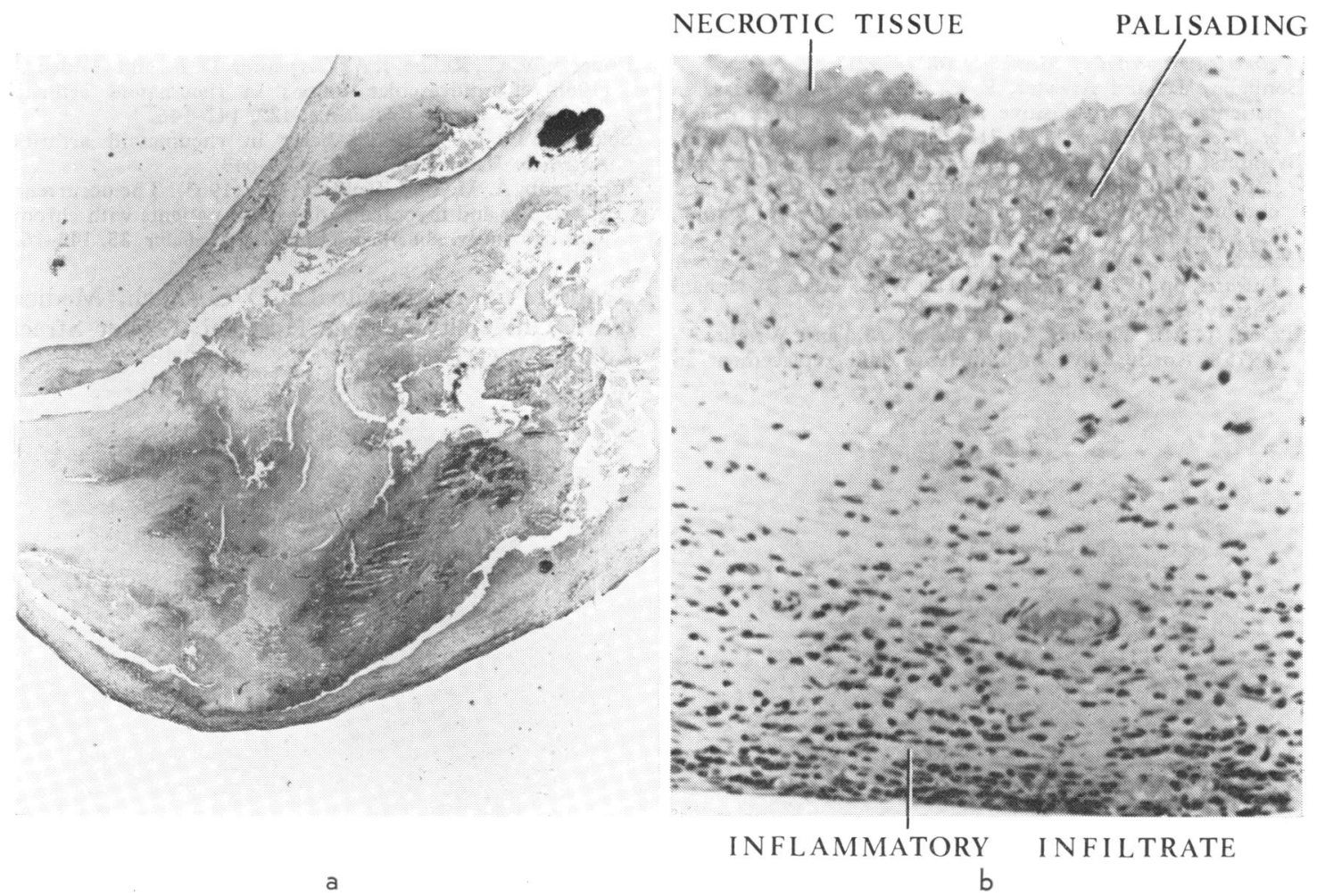

Fig. (a) Low power section of aortic valve cusp showing inflamed valve tissue, enclosing amorphous, partly calcified necroti tissue. ( $H$ and $E . \times 15$ original magnification.) (b) High power view of one side of the aortic valve showing inflammatory infiltrate rich in plasma cells on the luminal surface and poorly defined palisading along the edge of the necrotic zone. ( $H$ and $E . \times 180$ original magnification.)

abrupt deterioration in his condition. Iveson et al. (1975) reported one patient who required aortic valve replacement within six months of the appearance of signs of aortic regurgitation, but in other well-documented cases the progression has been slow. At operation the valve leaflets were soft and swollen and the left coronary cusp of the aortic valve appeared to prolapse in the absence of aortic root dilatation. We believe that this prolapse of the softened leaflet accounted for the sudden deterioration of the patient's clinical condition. The clinical observations, the preoperative echocardiogram, and the left ventriculogram showing normal ejection fraction, suggest that myocardial failure was not responsible for the sudden decline. The successful postoperative course further supports this view. Had prolapse of the leaflet not occurred at this stage it is likely that the leaflets would have become fibrosed and contracted, as reported in all other cases.

The sudden deterioration had suggested the possibility of infective endocarditis with cusp rupture as an alternative to acute rheumatoid aortic valve disease; clinical features and laboratory investigations failed to distinguish between these alternative diagnoses.

We wish to emphasise that rheumatoid aortic valve disease may be haemodynamically significant and that it can be rapidly progressive simulating aortic cusp rupture. Features suggestive of rheumatoid valve involvement in this case and in other reports are the presence of subcutaneous nodules, episcleritis, and pericardial effusion (Bevans et al., 1954; Weintraub and Zvaifler, 1963; Bonfiglio and Atwater, 1969; Iveson et al., 1975).

We thank Dr Lyal Watson for permission to report this patient who was under his care.

\section{References}

Baggenstoss, A. H., and Rosenberg, E. F. (1941). Cardiac lesions associated with chronic infectious arthritis. Archives of Internal Medicine, 67, 241-258.

Barker, A. (1971). Rheumatoid arthritis and rheumatoid heart disease. New Zealand Medical fournal, 73, 14-18. 
Bevans, M., Nachell, J., Demartini, E., and Ragan, C. (1954). The systemic lesions of malignant rheumatoid arthritis. American fournal of Medicine, 16, 197-211.

Bonfiglio, T., and Atwater, E. C. (1969). Heart disease in patients with sero-positive rheumatoid arthritis. Archives of Internal Medicine, 124, 714-721.

Bywaters, E. G. L. (1950). The relation between heart and joint disease including 'rheumatoid heart disease' and chronic post-rheumatic arthritis. British Heart fournal, 12, 101-131.

Charcot, J. M. (1881). Clinical Lectures on Senile and Chronic Diseases, pp. 172-175, translated by W. S. Tuke. Sydenham Society, London.

Iveson, J. M., Thadani, N., Ionescu, M., and Wright, V. (1975). Aortic valve incompetence and replacement in rheumatoid arthritis. Annals of the Rheumatic Diseases, 34, 312-320.

Roberts, W. C., Kehoe, J. A., Carpenter, D. F., and Golden, A. (1968). Cardiovascular lesions in rheumatoid arthritis. Archives of Internal Medicine, 122, 141-146.

Sokoloff, L. (1953). The heart in rheumatoid arthritis. American Heart fournal, 45, 635-643.

Weintraub, A. M., and Zvaifler, N. J. (1963). The occurrence of valvular and myocardial disease in patients with chronic joint deformity. American fournal of Medicine, 35, 145-162.

Requests for reprints to Dr D C Linch, Medical Unit, University College Hospital, Gower Street, London WC1E 6AU 